\title{
Potential of Earth's core as a reservoir for noble gases: Case for helium and neon
}

\author{
M.A. Bouhifd ${ }^{1,2 *}$, A.P. Jephcoat ${ }^{2,3}$, D. Porcelli ${ }^{2}$, S.P. Kelley ${ }^{4,}$, B. Marty ${ }^{5}$
}

Abstract

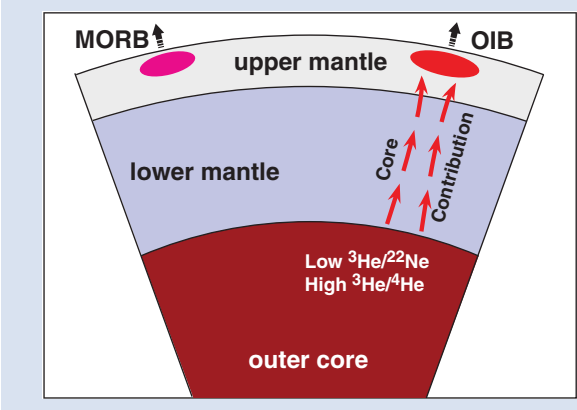

This study investigates metal-silicate partitioning of neon $\left(D_{\mathrm{Ne}}\right)$ under the likely conditions of early Earth's core formation: up to $16 \mathrm{GPa}, \sim 3000 \mathrm{~K}$ and an oxygen fugacity near IW-2 (2 log units below the Iron-Wüstite buffer). We find that the $D_{\mathrm{Ne}}$ coefficients range between $10^{-2}$ and $10^{-1}$. These partition coefficients are only one of the controlling factors of noble gas distributions within the early Earth: because, even if $D_{\mathrm{He}}$ and $D_{\mathrm{Ne}}$ are low $\left(\sim 10^{-4}\right)$, there may have been sufficient noble gases present in the mantle to supply a significant quantity of $\mathrm{He}$ and $\mathrm{Ne}$ to the core. Assuming gasmelt equilibrium of the molten proto-Earth with a nebular gas composition and concomitant metal-silicate differentiation, the core would have inherited and maintained throughout Earth's history high ${ }^{3} \mathrm{He} /{ }^{4} \mathrm{He}$ ratios and low ${ }^{3} \mathrm{He} /{ }^{22} \mathrm{Ne}$ ratios $(<0.6)$, making the core a potential source of primordial light noble gases in mantle plumes.

Received 13 December 2019 | Accepted 6 August 2020 | Published 9 September 2020

\section{Letter}

Earth's mantle contains a mixture of primordial noble gases, in particular solar-type helium and neon, and radiogenic noble gases (e.g., Marty, 2012; Moreira, 2013). The isotopic ratios of $\mathrm{He}$ and $\mathrm{Ne}$ in ocean island basalts (OIB) indicate the existence of a reservoir with high concentrations of primordial noble gases in the deep Earth. This reservoir appears to have been isolated from the MORB (Mid-Ocean Ridge Basalts) source reservoir 4.4 billion years ago (e.g., Pepin and Porcelli, 2006; Mukhopadhyay, 2012; and references therein).

The origin of high ${ }^{3} \mathrm{He} /{ }^{4} \mathrm{He}$ and low ${ }^{3} \mathrm{He} /{ }^{22} \mathrm{Ne}$ ratios in many OIBs is still much debated and there has long been a supposition that OIBs sample a primordial and undegassed reservoir located in the deep mantle. Increasing evidence for mantle convection processes has pushed the debated boundary for a primitive mantle source location ever deeper into the lower mantle, reaching the core-mantle boundary (e.g., Williams et al., 2019). The Earth's core has also been suggested as an alternative source of noble gases (Porcelli and Halliday, 2001; Trieloff and Kunz, 2005; Armytage et al., 2013; Bouhifd et al., 2013; Roth et al., 2019).

Extending our previous work on helium, here we investigate neon partitioning between molten silicates and Fe-rich alloy liquids up to $16 \mathrm{GPa}$ and to a maximum temperature of $\sim 3000 \mathrm{~K}$. We also address the behaviour of $\mathrm{He} / \mathrm{Ne}$ in an early magma ocean.
A CI-chondrite model composition was chosen for the starting silicate material (e.g., Bouhifd et al., 2013). To simulate Earth's core formation under conditions of segregation from a deep magma ocean, we performed experiments with a starting mix of CI-chondrite glass (66 wt. \%) with various Fe-rich alloys (34 wt. \%).

We used a set-up described in previous studies (e.g., Jephcoat et al., 2008) with all details reported in the Supplementary Information. Briefly, we used diamond anvils with $500 \mu \mathrm{m}$ culets, and stainless steel gaskets pre-indented to a thickness of $\sim 50 \mu \mathrm{m}$ and drilled to a diameter of $\sim 100 \mu \mathrm{m}$. Samples were mounted in the pressure chamber and neon was loaded with a high pressure gas-loading technique at $200 \mathrm{MPa}$. Pressures were measured using the ruby fluorescence method before and after each heating stage. The samples were heated by a $100 \mathrm{~W}$ air-cooled fibre laser with emission centred at $1070 \mathrm{~nm}$ for an average of about 15 minutes for each zone of the sample. During the heating stage the surrounding neon melted by conductive heating from the heated sample, allowing its dissolution into the sample. Temperatures were determined spectro-radiometrically with a fit to a grey-body Planck function. The temperatures of our runs were higher by at least 200 degrees than the liquidus temperature of peridotite (Zhang and Herzberg, 1994; Fig. S-2). Because our experiments are not routine the success of our LHDAC technique was demonstrated in our previous studies where we found a good agreement between

\footnotetext{
Laboratoire Magmas et Volcans, Université Clermont Auvergne, CNRS UMR 6524, OPGC-IRD, F-63000 Clermont-Ferrand, France

University of Oxford, Department of Earth Sciences, Parks Road, Oxford, OX1 3AN, UK

Institute for Planetary Materials, Okayama University, 827 Yamada, Misasa, Tottori 682-0193, Japan

Department of Environment, Earth and Ecosystems, Open University, Milton Keynes MK7 6AA, UK

Centre de Recherches Pétrographiques et Géochimiques, CNRS, UPR 2300, F-54501 Vandoeuvre-lès-Nancy, France

Present address: Grant Institute, The King's Buildings, James Hutton Road, Edinburgh EH9 3FE, UK

Corresponding author (email: ali.bouhifd@uca.fr)
} 
our results and those provided from large volume presses for argon (Fig. S-3a,b).

The chemical compositions of the run products were analysed by an electron microprobe (JEOL JXA-8800R with 4 wavelength dispersive spectrometers) with an accelerating voltage of $15 \mathrm{kV}$ and a beam current of $20 \mathrm{nA}$ (see Table S-1). The chemical analyses for neon with the UVLAMP were carried out at the Open University, UK. A NewWave UP213 combined laser/ microscope system uses a $10 \mathrm{~Hz}$ quintupled Nd-YAG laser with a wavelength of $213 \mathrm{~nm}$ yielding $\sim 10 \mathrm{~ns}$ pulses (Heber et al., 2007). The extracted gas was cleaned using three SAES AP-10 getters at $400{ }^{\circ} \mathrm{C}$ and room temperature to remove active gases before analysis with a MAP 215-50 noble gas mass spectrometer. Blanks were measured before and after each ablation and all the measured blanks were small with respect to the minimum neon concentrations measured in our samples. For both silicate and metal analyses, the measured ${ }^{22} \mathrm{Ne}$ blanks were $(0.6 \pm 0.1) \times$ $10^{-12} \mathrm{~cm}^{3}$ STP. To convert measured Ne abundances into concentrations, the volumes of all laser pits were determined by using a non-contact, vertical scanning white light interferometer (Zygo instrument), which has a vertical resolution of $\sim 1 \AA$ and a horizontal resolution of $1 \mu \mathrm{m}$.

The experimental conditions, the neon contents of the run products and the resulting partition coefficients for neon are presented in Table 1. Each of the reported results is the average of several spot analyses made from the same phase. During $\mathrm{Ne}$ analysis, we ablated the first 2 microns from the surface before starting the quantitative determinations of $\mathrm{Ne}$ concentrations. This step is made to avoid the high near-surface concentrations of noble gases (e.g., Bouhifd et al., 2013). Therefore, the neon contents presented here correspond to neon dissolved in the bulk molten phases quenched from HP.

Here we found that the neon solubility in silicate melt dropped by a factor of $\sim 3$ (Fig. 1) from $\sim 450 \mathrm{ppm}$ Ne at $6 \mathrm{GPa}$ to $\sim 140 \mathrm{ppm} \mathrm{Ne}$ at $10 \mathrm{GPa}$. This drop of neon solubility can be attributed to the characteristic of silicate melts at high pressures as reported in our study for argon (Bouhifd and Jephcoat, 2006). We also found no evidence for a pressure dependence of Ne solubility in Fe-rich alloys. It is important to note here that the drop of Ne solubility in silicate melt by a factor of 3 will only vary the $D_{\mathrm{Ne}}$ coefficient from $3 \times 10^{-2}$ at $6 \mathrm{GPa}$ (before the drop of Ne solubility in the silicate melt) to $9.8 \times 10^{-2}$ at $10 \mathrm{GPa}$ (after the drop of $\mathrm{Ne}$ solubility). The

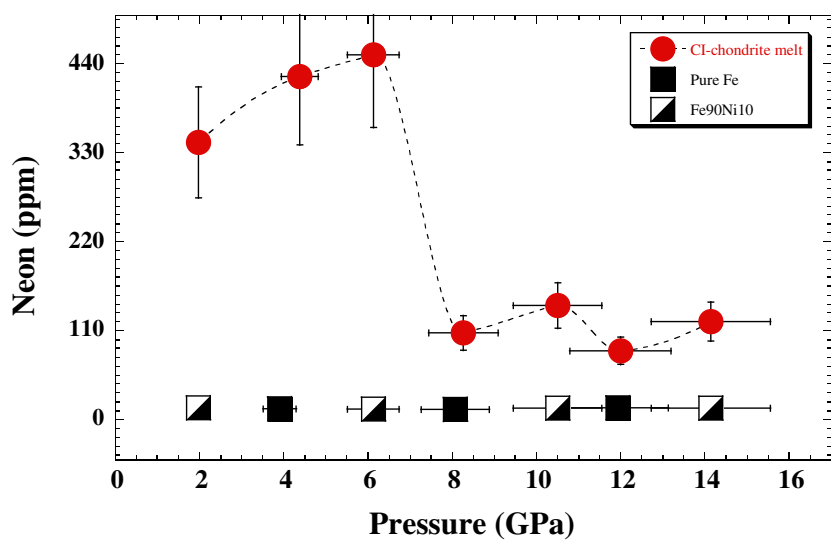

Figure 1 Neon concentrations in $\mathrm{Cl}$-chondrite melt, $\mathrm{Fe}$ and $\mathrm{Fe}_{90} \mathrm{Ni}_{10}$ alloy at high pressures. The reported $\mathrm{Ne}$ contents represent the average of 5 to 20 analyses. Error bars correspond to $1 \sigma$ (ranging from 5 to $20 \%$ ) of the average of the chemical analyses and to $10 \%$ of the nominal pressures reported. For the metallic phase no pressure dependence is observed and the average value of Ne concentrations is $13.5 \pm 0.8 \mathrm{ppm}$.

variation of $D_{\mathrm{Ne}}$ of less than one order of magnitude was taken into account in our calculations and was found not to affect the main conclusion of the present work. Previous studies show that the core can be a plausible source for light noble gases using much lower $\left(\sim 10^{-4}\right)$ partition coefficients of $\mathrm{He}$ and $\mathrm{Ne}$, meaning that the metal-silicate partition coefficients of noble gases are not the only limiting factor. The main controlling factor being the abundances of noble gases in the proto-Earth (Porcelli and Halliday, 2001; Trieloff and Kunz, 2005).

Measurements of Ne partitioning between metal and silicate have been reported by Matsuda et al. (1993) and Sudo et al. (1994). These studies indicate high $D_{\mathrm{Ne}}$ of $\sim 10^{-1}$ at $\mathrm{P} \sim 0.5 \mathrm{GPa}$ that decreased with increasing pressure to near $10^{-3}$ at $6 \mathrm{GPa}$. At about $2 \mathrm{GPa}$, our $D_{\mathrm{Ne}}$ value is similar to that determined by Matsuda et al. (1993). However, at pressures $\geq 2 \mathrm{GPa}$, we do not observe the systematic decrease in the $D_{\mathrm{Ne}}$ coefficients, instead our results indicate higher $D_{\mathrm{Ne}}$ coefficients of $\sim 10^{-1}$ at pressures $>8 \mathrm{GPa}$, which is little dependent on pressure (Fig. 2). This behaviour is similar to that of helium for which we found that $D_{\mathrm{He}}$ coefficients are constant over a wide range

Table 1 Neon concentrations (ppm) in molten Cl-chondrite and Fe-rich alloys liquids. Values in bold (either for metallic or silicate phases) are linear interpolations between the two nearest experimental pressure data.

\begin{tabular}{|c|c|c|c|c|}
\hline \multirow{2}{*}{$\mathrm{P}(\mathrm{GPa})$} & \multirow{2}{*}{$\mathrm{T}(\mathrm{K})$} & Ne contents (ppm) & Ne contents (ppm) & \multirow{2}{*}{$D_{\mathrm{Ne}}$} \\
\hline & & CI-Chondrite melt & Fe-rich alloy liquids & \\
\hline 2.0 & 2400 & $342( \pm 25)$ & $14.3( \pm 1.3)$ & $4.2( \pm 0.7) \times 10^{-2}$ \\
\hline 4.4 & 2400 & $424( \pm 36)$ & $13.4( \pm 1.0)$ & $3.2( \pm 0.5) \times 10^{-2}$ \\
\hline 6.1 & 2500 & $451( \pm 32)$ & $12.8( \pm 1.0)$ & $2.8( \pm 0.4) \times 10^{-2}$ \\
\hline 8.3 & 2450 & $107( \pm 9)$ & $12.1( \pm 1.0)$ & $1.1( \pm 0.2) \times 10^{-1}$ \\
\hline 10.5 & 2500 & $141( \pm 15)$ & $13.8( \pm 1.5)$ & $9.8( \pm 2.1) \times 10^{-2}$ \\
\hline 12.0 & 2500 & $85( \pm 8)$ & $14.0( \pm 1.5)$ & $1.6( \pm 0.3) \times 10^{-1}$ \\
\hline \multirow[t]{2}{*}{14.1} & 2700 & $121( \pm 14)$ & $14.0( \pm 2.0)$ & $1.2( \pm 0.3) \times 10^{-1}$ \\
\hline & & & Pure Iron & \\
\hline 3.9 & 2200 & $420( \pm 40)$ & $13.4( \pm 1.0)$ & $3.2( \pm 0.5) \times 10^{-2}$ \\
\hline 8.1 & 2200 & $110( \pm 10)$ & $12.1( \pm 1.0)$ & $1.1( \pm 0.2) \times 10^{-1}$ \\
\hline
\end{tabular}




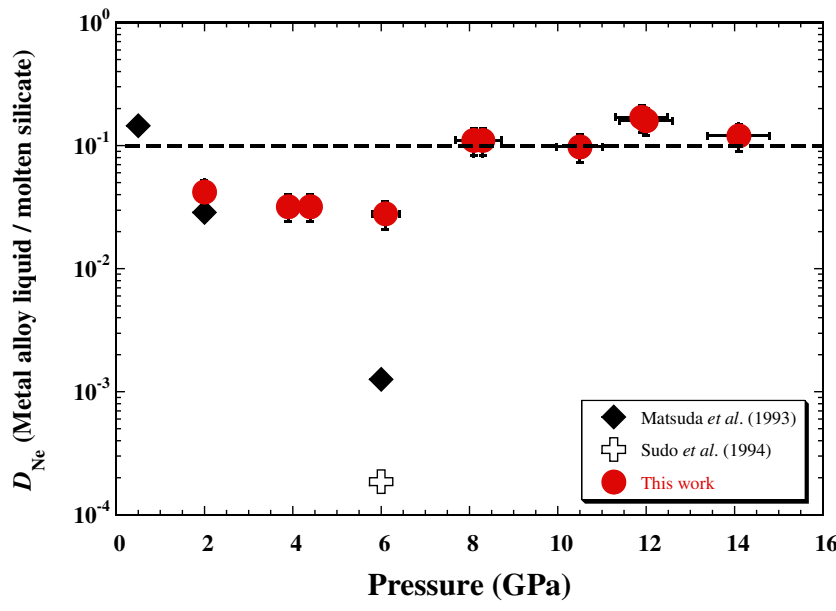

Figure 2 Partition coefficients of Neon, $D_{\mathrm{Ne}}$ (wt. \% of Ne in metallic phase / wt. \% of $\mathrm{Ne}$ in silicate) between molten silicate and iron-rich metal liquids as a function of pressure. The average value of our experiments at high pressure is represented by the dashed line. The previous data from Matsuda et al. (1993) and Sudo et al. (1994) are also plotted. At this stage the discrepancy between data sets at $6 \mathrm{GPa}$ is unknown.

of pressure up to $40 \mathrm{GPa}$ (Bouhifd et al., 2013). We assume thus that the $D_{\mathrm{Ne}}$ is within $10^{-2}-10^{-1}$ at the conditions of Earth's core formation that can reach conditions in the range of 30-70 GPa and $3500 \mathrm{~K}$ as determined from moderately siderophile elements.

Assuming a global magma ocean during core formation, our experimental solubilities of $\mathrm{Ne}$ and $\mathrm{He}$ into a chondritic melt show that under a hot, dense atmosphere from which volatiles are dissolved, such a magma ocean would have been enriched in He with respect to Ne. The reported [He/Ne] ratio (wt. \% of $\mathrm{He} / \mathrm{wt}$. \% of $\mathrm{Ne}$ in chondritic melt) shows a negligible dependence on pressure up to $17 \mathrm{GPa}$ with an average of $6 \pm 2$ (Fig. 3). Because the solubility factor ratio of $\mathrm{He}$ by $\mathrm{Ne}$ is at most 2 (e.g., Jambon et al., 1986), an early magma ocean would have presented a ratio ${ }^{3} \mathrm{He} /{ }^{22} \mathrm{Ne}$ within $2.5-5$, reflecting up to two global melting events during the first 100 million years of Earth's history (Tucker and Mukhopadhyay, 2014). For the estimate above, we consider that the initial ${ }^{3} \mathrm{He} /{ }^{22} \mathrm{Ne}$ ratio is that of the solar nebula or of implanted solar wind during the early

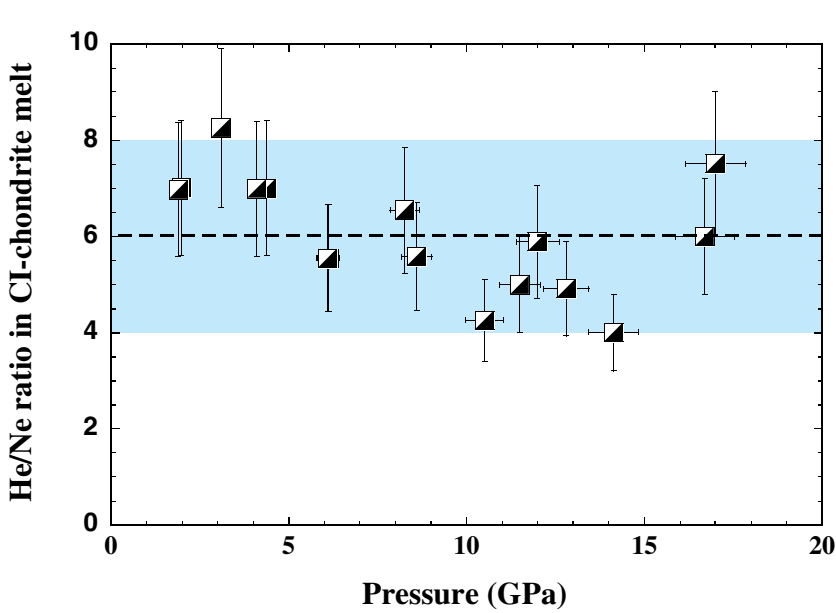

Figure $3 \mathrm{He} / \mathrm{Ne}$ ratio (wt. \% of $\mathrm{He}$ in the melt / wt. \% of $\mathrm{Ne}$ in the melt) in Cl-chondrite melt at high pressures. solar system, around $1.50 \pm 0.06$, and $0.9 \pm 0.1$, respectively (e.g., Yokochi and Marty, 2004; Heber et al., 2009; Raquin and Moreira, 2009; Tucker and Mukhopadhyay, 2014).

In order to evaluate the potential of $\mathrm{He}$ and $\mathrm{Ne}$ sequestration by the core, it is necessary to estimate the initial abundances of these noble gases on proto-Earth. In the early part of Earth's history, high concentrations of $\mathrm{He}$ and $\mathrm{Ne}$ that might have existed as Xe isotopes indicate extensive losses of volatile elements from the mantle within the first 100 Myr. Such losses appear to have depleted the noble gases by $\geq 97 \%$, implying that their initial concentrations in Earth were two orders of magnitude higher than at present (Porcelli et al., 2001; Yokochi and Marty, 2005). The amounts of primitive helium and neon can thus be estimated from the present day ${ }^{3} \mathrm{He}$ and ${ }^{22} \mathrm{Ne}$ concentrations in the mantle that range between 2.2 and $>14 \times 10^{-10}$ cc STP/g for ${ }^{3} \mathrm{He}$ and between 4 and $>58 \times 10^{-11} \mathrm{cc} \mathrm{STP} / \mathrm{g}$ for ${ }^{22} \mathrm{Ne}$ (Yokochi and Marty, 2004; Moreira and Kurz, 2013). We can thus estimate that ${ }^{3} \mathrm{He}$ primitive mantle's concentrations are in the range of $\sim 10^{12}{ }^{3} \mathrm{He}$ atoms/g. In addition, the initial Earth ${ }^{3} \mathrm{He} /{ }^{4} \mathrm{He}$ ratio was around $120 \times \mathrm{R}_{\mathrm{A}}$ (where $\mathrm{R}_{\mathrm{A}}=1.39 \times$ $10^{-6}$ is the atmospheric ratio) if solar nebula was trapped in the mantle; or $330 \times \mathrm{R}_{\mathrm{A}}$ that represents the solar wind ratio, provided that terrestrial He was derived from solar wind implantation of accreting materials (Porcelli et al., 2001).

By considering the values reported above, abundances of about $2.7 \times 10^{12}{ }^{3} \mathrm{He}$ atoms $/ g$ and $2.9 \times 10^{12}{ }^{22} \mathrm{Ne}$ atoms $/ g$ in the early Earth's mantle are very plausible. By taking these values as the initial ${ }^{3} \mathrm{He}$ and ${ }^{22} \mathrm{Ne}$ abundances at time of the core formation, and the measured $D_{\mathrm{He}}$ and $D_{\mathrm{Ne}}{ }^{3} \mathrm{He}$ and ${ }^{22} \mathrm{Ne}$ in the early core could have been between $1.3 \times 10^{10}$ and $4.6 \times 10^{10}{ }^{3} \mathrm{He}$ atoms $/ g$, and between $8.1 \times 10^{10}$ and $4.9 \times 10^{11}{ }^{22} \mathrm{Ne}$ atoms $/ g$, respectively. These estimates indicate that the Earth's early core might have had a ${ }^{3} \mathrm{He} / 22 \mathrm{Ne}$ ratio lower than 0.6. During core formation, the ${ }^{3} \mathrm{He} /{ }^{22} \mathrm{Ne}$ ratio of the mantle should be within the range 2.5-5, and the metal-silicate partition coefficient of the $\mathrm{He} / \mathrm{Ne}$ ratio is about $5 \times 10^{-2}$ (Fig. S-9) leading to a ${ }^{3} \mathrm{He} /$ ${ }^{22} \mathrm{Ne}$ ratio within the core in the range of $0.12-0.25$. We can thus conclude that the Earth's core must have inherited low ${ }^{3} \mathrm{He} /{ }^{22} \mathrm{Ne}$ ratio $(<0.6)$, and any contribution from the core to the OIBs source regions has the potential to lower their ${ }^{3} \mathrm{He} /{ }^{22} \mathrm{Ne}$ ratios.

The measured high ${ }^{3} \mathrm{He} /{ }^{4} \mathrm{He}$ and low ${ }^{3} \mathrm{He} /{ }^{22} \mathrm{Ne}$ ratios observed now in some OIBs (such as Hawaii) could be the result from mixing of $\mathrm{He}$ and $\mathrm{Ne}$ from a small core component with radiogenic ${ }^{4} \mathrm{He}$ and residual ${ }^{3} \mathrm{He}$ and ${ }^{22} \mathrm{Ne}$ from the mantle. Our new estimates, based on the ratio of the fluxes of noble gases in OIBs to their concentrations in the core, would require that less than $1 \%$ of the mass of the core should have released its primordial light noble gases.

Since significant amounts of siderophile elements are incorporated in the core, additions of core material to the OIBs would impact these elements. For modern OIBs, tungsten isotopic data negatively correlate with ${ }^{3} \mathrm{He} /{ }^{4} \mathrm{He}$ ratios (Mundl et al., 2017). This correlation can indicate core-mantle interaction with transfer of the high ${ }^{3} \mathrm{He} /{ }^{4} \mathrm{He}$ and low ${ }^{182} \mathrm{~W}$ signature of the outer core to the source of the OIBs. A similar conclusion was reached in a more recent study by Rizo et al. (2019) where they found that core-mantle exchange might be facilitated by exsolution of $\mathrm{W}$-rich, $\mathrm{Si}-\mathrm{Mg}$-Fe oxides from the core into the mantle. A correlation between the highest ${ }^{3} \mathrm{He} /{ }^{4} \mathrm{He}$ values and the highest ${ }^{186} \mathrm{Os} /{ }^{188} \mathrm{Os}$ ratios in Hawaii was also used as an evidence for a core contribution to He and Os (Walker et al., 1995). However, subsequent studies in other OIBs show that this evidence in OIBs cannot be uniquely tied to the core (Luguet et al., 2008). Clearly, the debate over core-mantle exchanges has some way to go, but the present study shows that the early Earth's core 
could have incorporated helium and neon making it a potential supplier of light noble gases into deep-rooted mantle plumes. Also the Earth's core must have inherited high ${ }^{3} \mathrm{He} /{ }^{4} \mathrm{He}$ ratios (in the range $120-330$ ) and low ${ }^{3} \mathrm{He} /{ }^{22} \mathrm{Ne}$ ratios $(<0.6)$, and the core maintained high and low, ${ }^{3} \mathrm{He} /{ }^{4} \mathrm{He}$ and ${ }^{3} \mathrm{He} /{ }^{22} \mathrm{Ne}$ ratios, respectively, throughout Earth's history.

\section{Acknowledgements}

To the memory of our friend and colleague Pete Burnard with whom we have had many discussions about the origin of noble gases on Earth. We would like to thank Steve Parman and an anonymous reviewer for comments and suggestions that help us to improve our manuscript. MAB acknowledges the support of a NERC and the PNP-CNRS program. This work was also supported by NERC grants to APJ. This is Laboratory of Excellence ClerVolc contribution number 429.

Editor: Helen Williams

\section{Additional Information}

Supplementary Information accompanies this letter at http:// www.geochemicalperspectivesletters.org/article2028.

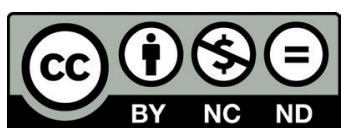

(C) 2020 The Authors. This work is distributed under the Creative Commons Attribution NonCommercial No-Derivatives 4.0 License, which permits unrestricted distribution provided the original author and source are credited. The material may not be adapted (remixed, transformed or built upon) or used for commercial purposes without written permission from the author. Additional information is available at http://www. geochemicalperspectivesletters.org/copyright-and-permissions.

Cite this letter as: Bouhifd, M.A., Jephcoat, A.P., Porcelli, D., Kelley, S.P., Marty, B. (2020) Potential of Earth's core as a reservoir for noble gases: Case for helium and neon. Geochem. Persp. Let. 15, 15-18.

\section{References}

Armytage, R., Jephcoat, A.P., Bouhifd, M.A., Porcelli, D. (2013) Metal-silicate partitioning of iodine at high pressures and temperatures: implications for the Earth's core and ${ }^{129} \mathrm{Xe}$ budgets. Earth and Planetary Science Letters $373,140-149$.

BOUHIFD, M.A., JEPHCOAT, A.P. (2006) Aluminium control of argon solubility in silicate melts under pressure. Nature 439, 961-964

BouhifD, M.A., JePhCOAT, A.P., Heber, V.S., Kelley, S.P. (2013) Helium in Earth's early core. Nature Geoscience 6, 982-986.

Heber, V.S., BRoOKer, R.A., Kelley, S.P., WoOd, B.J. (2007) Crystal-melt partitioning of noble gases (helium, neon, argon, krypton and xenon) for olivine and clinopyroxene. Geochimica et Cosmochimica Acta 71, 1041-1061.

Heber, V.S., Wieler, R., Baur, H., Olinger, C., Friedmann, T.A., Burnett, D.S. (2009) Noble gas composition of the solar wind as collected by the Genesis mission. Geochimica et Cosmochimica Acta 73, 7414-7432.

Jambon, A., Weber, H., Braun, O. (1986) Solubility of $\mathrm{He}, \mathrm{Ne}, \mathrm{Ar}, \mathrm{Kr}$ and Xe in a basalt melt in the range $1250-1600{ }^{\circ} \mathrm{C}$ : Geochemical implications. Geochimica et Cosmochimica Acta 50, 401-408.

JePHCOAT, A.P., BouHIFD, M.A., PorCelli, D. (2008) Partitioning experiments in the laser-heated diamond anvil cell: volatile content in the Earth's core. Philosophical Transactions Royal Society A 366, 4295-4314.

Luguet, A., Pearson, D.G., Nowell, G.M., Dreher, S.T., Coggon, J.A., Spetsius, Z.V., PARman, S.W. (2008) Enriched Pt-Re-Os isotope systematics in plume lavas explained by metasomatic sulfides. Science 319, 453-456.

MARTY, B. (2012) The origins and concentrations of water, carbon, nitrogen and noble gases on Earth. Earth and Planetary Science Letters 313-314, 56-66.
Matsuda, J., Sudo, M., Ozima, M., Ito, K., Ohtaka, O., Ito, E. (1993) Noble gas partitioning between metal and silicate under high pressures. Science 259, 788-790.

MoreIRA, M. (2013) Noble gas constraints on the origin and evolution of Earth's volatiles. Geochemical Perspectives 2, 229-403.

Moreira, M., KuRz, M.D. (2013) Noble gases as tracers of mantle processes and magmatic degassing. In: BurnarD, P. (Ed.) The Noble Gases as Geochemical Tracers. Advances in Isotope Geochemistry. Springer-Verlag, Berlin, Heidelberg, 371-391.

MuKHOPADHYAY, S. (2012) Early differentiation and volatile accretion recorded in deep-mantle neon and xenon. Nature 486, 101-104.

Mundl, A., Touboul, M., Jackson, M.G., DAy, J.M.D., Kurz, M.D., Lekic, V., Helz, R.T., WaLKER, R.J. (2017) Tungsten-182 heterogeneity in modern ocean island basalts. Science 356, 66-69.

Pepin, R.O., Porcelli, D. (2006) Xenon isotope systematics, giant impacts, and mantle degassing on the early Earth. Earth and Planetary Science Letters 250, 470-485.

Porcelli, D., Halliday, A.N. (2001) The core as a possible source of mantle helium. Earth and Planetary Science Letters 192, 45-56.

Porcelli, D., Wollun, D., Cassen, P. (2001) Deep Earth rare gases: initial inventories, capture from the solar nebula, and losses during Moon formation. Earth and Planetary Science Letters 193, 237-251.

RAQUin, A., MoreIRA, M. (2009) Atmospheric ${ }^{38} \mathrm{Ar} /{ }^{36} \mathrm{Ar}$ in the mantle: implications for the nature of the terrestrial parent bodies. Earth and Planetary Science Letters 287, 551-558.

Rizo, H., Andrault, D., Bennett, N.R., Humayun, M., Brandon, A., Vlastelic, I., Moine, B., Poirier, A., Bouhifd, M.A., Murphy, D.T. (2019) ${ }^{182}$ W evidence for core-mantle interaction in the source of mantle plumes. Geochemical Perspectives Letters 11, 6-11.

Roth, A.S.G., LiebsKe, C., Maden, C., Burton, K.W., SChÖnbächler, M., Busemann, H. (2019) The primordial He budget of the Earth set by percolative core formation in planetesimals. Geochemical Perspectives Letters 9, 26-31.

Sudo, M., OhtAKa, O., Matsuda, J. (1994) Noble gas partitioning between metal and silicate under high pressures: The case of iron and peridotite. In: Matsuda, J. (Ed.) Noble Gas Geochemistry and Cosmochemistry. Terra Scientific Publishing Company (TERRAPUB), Tokyo, 355-372.

Trieloff, M., KunZ, J. (2005) Isotope systematics of noble gases in the Earth's mantle: possible sources of primordial isotopes and implications for mantle structure. Physics of the Earth and Planetary Interiors 148, 13-38.

TUCKER, J.M., MuKHOPADHYAY, S. (2014) Evidence for multiple magma ocean outgassing and atmospheric loss episodes from mantle noble gases. Earth and Planetary Science Letters 393, 254-265.

WaLKer, R.J., Morgan, J.W., Horan, M.F. (1995) Osmium-187 enrichment in some plumes: evidence for core-mantle interaction? Science 269, 819-822.

Williams, C.D., Mukhopadhyay, S., Rudolph, M.L., Romanowicz, B. (2019) Primitive helium is sourced from seismically slow regions in the lower most mantle. Geochemistry, Geophysics, Geosystems 20, 4130-4145.

YOKOCHI, R., MARTY, B. (2004) A determination of the neon isotopic composition of the deep mantle. Earth and Planetary Science Letters 225, 77-88.

YoKOCHI, R., MARTY, B. (2005) Geochemical constraints on mantle dynamics in the Hadean. Earth and Planetary Science Letters 238, 17-30.

ZHANG, J., HerzBerg, C. (1994) Melting experiments on anhydrous peridotite KLB-1 from 5.0 to 22.5 GPa. Journal of Geophysical Research 99, 17729-17742. 